\title{
PRODUC̣ÃO TEXTUAL EM DIFERENTES GÊNEROS: UM CASO NA FORMAÇÃO DE PROFESSORES DE QUÍMICA
}

Wilmo Ernesto Francisco Junior*

RESUMO: A presente pesquisa relata atividade de leitura conduzida com licenciandos em Química de uma universidade federal. A leitura, conduzida em período extraclasse, foi acompanhada da produção de textos (em grupos de no máximo três pessoas) que deveriam corresponder a quatro gêneros distintos: carta, poesia, história em quadrinhos e artigo de opinião. As produções textuais apresentaram qualidades diversificadas, como criatividade e emprego de variados recursos linguísticos. Histórias em quadrinhos e poesias, talvez por serem gêneros artísticos, possibilitaram maior liberdade de criação. Já as cartas e os artigos de opinião foram compostos de maior diversidade de tipos textuais. Não foram observadas cópias literais da obra lida, indicando que a escrita de um texto em gênero diferente daquele lido permite o afloramento de características da leitura crítica, como a criação de um texto próprio e a recriação de sentidos.

Palavras-chave: Escrita; Leitura; Gêneros Textuais.

\section{TEXT PRODUCTION IN DIFFERENT GENRES: A CASE IN THE CHEMISTRY TEACHER EDUCATION}

ABSTRACT: In this study, we report a reading activity performed with chemistry undergraduate students from a federal university. Reading was not performed during classroom time and the activity also involved text production, in groups of up to three people, in four distinct writing genres: letter, poem, cartoon strip and essay. Text productions evidenced different qualities such as creativity and variety of linguistic resources. Results also showed that cartoon strips and poems allowed greater freedom in textual expression, perhaps because of their artistic characteristics, while letters and essays comprised a greater diversity of text types. Literal copies were not observed, indicating that the writing of a text in a distinct genre allowed students to express important aspects of critical reading, such as one's own creation of texts and the recreation of ideas from reading.

Keywords: Writing; Reading; Text Genres.

\footnotetext{
*Doutor em Química pelo Instituto de Química da Universidade Estadual Paulista (UNESP/Araraquara); Professor da Universidade Federal de Alagoas (UFAL/Arapiraca). E-mail: wilmojr@bol.com.br
} 


\section{INTRODUC̣ÃO}

A diversidade de gêneros textuais inseridos no cotidiano exige que bons leitores sejam leitores versáteis, capazes de compreender e interpretar diferentes mensagens veiculadas pelos diferentes suportes. Torna-se imprescindível que o ensino da leitura proporcione aos educandos o contato com esses diferentes materiais. O leitor não se constitui a partir de um único texto ou um único gênero de texto. É importante que os educandos conheçam os diferentes gêneros textuais, mobilizando variados recursos de leitura, sendo a importância de se trabalhar com a diversidade dos gêneros textuais destacada por vários autores (KLEIMAN, 2001; KOCH; ELIAS, 2010; SILVA, 2003).

No ato comunicativo, por exemplo, o agente deve escolher o gênero mais apropriado para a mensagem que será veiculada. É a competência comunicativa, que se desenvolve com a competência leitora, de escrita e de fala, que propicia aos indivíduos decidirem o que é mais ou menos adequado em uma prática social comunicativa.

A escolha do gênero é, pois, uma decisão estratégica, que envolve uma confrontação entre os valores atribuídos pelo agente produtor aos parâmetros da situação (mundos físico e sociossubjetivo) e os usos atribuídos aos gêneros [...]. A escolha do gênero deverá [...] levar em conta os objetivos visados, o lugar social e os papéis dos participantes. Além disso, o agente deverá adaptar o modelo do gênero a seus valores particulares, adotando um estilo próprio, ou mesmo contribuindo para a constante transformação dos modelos. $(\mathrm{KOCH}$, 2009, p. 55-56).

Assumindo a indissociabilidade leitura-escrita-fala, para além da leitura de diferentes gêneros, é então preciso promover a escrita de diferentes gêneros, propiciando, de tal maneira, a entrada dos indivíduos no mundo da escrita de variados gêneros, como também a possibilidade de eles escolherem-nos e desenvolverem modelos próprios. Acredita-se, com isso, que os sujeitos tornem-se mais capazes de controlar o processo de leitura e escrita, efetivando-o no domínio da metacognição e tornando-se mais competentes.

Os gêneros textuais podem ser compreendidos “[...] como práticas socialmente constituídas com propósito comunicacional configuradas em textos." (KOCH; ELIAS, 2010, p. 56). Tais textos, por sua vez, são 
caracterizados basicamente por sua configuração em "[...] enunciados relativamente estáveis em cuja constituição entram elementos referentes ao conteúdo, composição e estilo.” (KOCH; ELIAS, 2010, p. 56). Logo, os gêneros possuem formatos relativamente estáveis na estruturação de um todo (KOCH; ELIAS, 2010). Ao mesmo tempo, um texto é formado por diferentes sequências ou tipos textuais, que são esquemas linguísticos básicos da composição dos diversos gêneros, podendo variar mais ou menos conforme a circunstância social. Os tipos textuais são basicamente descritivos, narrativos, injuntivos, explicativos (ou expositivos), argumentativos e dialogais.

Em uma narração, a marcação temporal cronológica é fundamental, fato sinalizado por diversos momentos durante o texto. Há predominância de verbos de ação. Os agentes das ações, materializados por meio de personagens, são também essenciais. Por sua vez, na estrutura expositiva a ênfase está nas ideias e não nas ações, sendo a orientação temporal irrelevante (KLEIMAN, 2008). A estrutura expositiva se organiza em componentes ligados entre si por relações lógicas, tais quais premissa e conclusão, problema e solução, causa e efeito, analogia, comparação, definição e exemplo (KLEIMAN, 2008). Essa estruturação é comum ao texto científico. Já a descrição é um tipo de estrutura mais imprecisa e, geralmente, encontra-se no seio de uma narração ou exposição. Pode ser reconhecida pela presença de agentes descritivos com efeito de listagem (seleção de qualidades e elementos do objeto em questão), efeito de qualificação (acúmulo de objetivos e orações adjetivas) e efeito de particularização do objeto. Tem-se a análise ou síntese de representações conceituais (KOCH; ELIAS, 2010). Também a orientação é atemporal. Predominam verbos de estado e situação.

No caso de sequências argumentativas, o autor busca convencer o leitor de algo. As descrições podem ser elogiosas, caso o autor queira destacar o mérito de algo, ou pouco elogiosas, se o objetivo for desmerecer. No contexto global, o discurso argumentativo tem marcas formais e componentes do texto que funcionam para esse objetivo, como ordenação lógica de argumentos ou contra-argumentos. Predominam elementos modalizadores, verbos que introduzem opinião. Quanto às sequências injuntivas, essas prescrevem ações e comportamentos, sendo suas principais marcas formais os verbos no imperativo, infinitivo ou futuro do presente (KOCH; ELIAS, 2010). Já as sequências dialogais se caracterizam pelo discurso direto. 
Reconhecer as marcas formais no texto e perceber a intenção discursiva do autor para ponderar, aceitar, refutar, julgar é fundamental para o leitor, aqui assumido como um sujeito ativo que, por meio de suas dimensões cognitivas e sociais, interage dialogicamente com o texto em um processo cooperativo com o qual um novo texto é produzido a partir da leitura. E isso só é possível se o leitor for capaz de dominar o conhecimento textual, suas diferentes formas e estruturas. Quanto mais contato com essas diferentes estruturas, mais capacitado o leitor estará para interagir com elas e com o autor para, consequentemente, assumir e manifestar pontos de vista com coerência. Na medida em que os leitores se tornam aptos a controlar o processo de leitura, percebendo-o não mais como uma estrutura superficial, mas sim uma estrutura complexa que relaciona homem e mundo, podem inquietarem-se e aumentarem a compreensão de si e do mundo que os cerca.

$\mathrm{O}$ ato de ler envolve uma direção da consciência para a expressão referencial escrita, capaz de gerar pensamento e doação de significado. A leitura (ou a resultante do ato de atribuir-se um significado ao discurso escrito) passa a ser, então, uma via de acesso à participação do homem nas sociedades letradas [...] (SILVA, 2002, p. 64).

Além disso, a partir da reflexão sobre os escritos produzidos é possível auxiliar os estudantes a monitorarem suas dificuldades, possibilitando a regulação desse processo. Nesses termos, este trabalho descreve uma atividade que envolveu a leitura de um livro, seguida da produção textual em gêneros variados e diferentes daquele lido. $\mathrm{O}$ intuito foi avaliar as contribuições da escrita em diferentes gêneros textuais à formação do leitor, a partir da seguinte questão: de que forma, a partir do domínio da escrita, os estudantes se manifestam a respeito da leitura?

\section{PROCEDIMENTOS METODOLÓGICOS}

A presente pesquisa foi desenvolvida nos meses de maio e junho de 2010 com licenciandos em Química da Universidade Federal de Rondônia - UNIR que cursavam a disciplina química analítica I. O texto selecionado para a leitura foi a obra $A$ ciência é masculina? É sim senhora!, de Attico Chassot (2009). A escolha de um livro e especificamente dessa obra 
foi movida por três características centrais. A primeira delas é a própria estrutura do texto. Trata-se de um texto mais longo, que possui muitas informações cujas ligações abarcam o uso de variados recursos linguísticos. A segunda característica é o fato de a obra proporcionar uma discussão acerca de um importante tema, que se acredita de fundamental relevância em cursos de formação docente: o sexismo ${ }^{1}$. Ao mesmo tempo, a partir de como a obra foi organizada, é possível introduzir elementos da história e da filosofia da ciência.

Inicialmente foram expostas todas as etapas da pesquisa aos estudantes, que aquiesceram em participar e adquirir a obra. Após a aquisição, foi efetuada a leitura na íntegra, em período extraclasse. Os estudantes tiveram quatro semanas para a leitura do livro. Foi solicitada, além da leitura, a produção de textos escritos, realizada em grupos (máximo de três pessoas), que deveriam corresponder a quatro gêneros distintos: carta, poesia, história em quadrinhos e artigo de opinião. A escolha pelos gêneros foi de livre opção, desde que não houvesse diferenças significativas entre a quantidade de cada um. Também não foram fornecidas orientações sobre as características textuais de cada gênero, apenas sugerido que eles procurassem ler os gêneros em questão para subsidiar a escrita. Vale ainda destacar que a participação em todas as atividades programadas poderia resultar em um acréscimo de até $20 \%$ na nota final da disciplina.

A produção textual foi norteada por uma exigência, assim apresentada aos educandos: Pesquise entre os ganhadores de prêmios Nobel quantos são mulheres e quantos são negros. Em sua opinião, qual(is) a(s) possível(eis) razão(ões) das diferenças observadas? Essa foi uma questão norteadora que funcionou como atividade de pré-leitura, direcionando o ato de ler e auxiliando a ativação de estruturas do conhecimento, sobretudo objetivos de leitura e elaboração de hipóteses. Apesar de nortear a leitura, a questão ainda permite abertura na produção de sentidos que a respondam, pois realça o papel do leitor ("Em sua opinião") em construir hipóteses (possíveis razões).

$\mathrm{Na}$ etapa seguinte, os educandos tiveram a possibilidade de dialogar com o autor do livro em palestra proferida durante o período da pesquisa. Conversas informais em horários extraclasse com os professores e entre os colegas também foram bastante comuns. Após, na última etapa, os educandos produziram, também em grupo, outro texto, em gênero 
diferente do primeiro. A produção desse texto ocorreu após eles assistirem a palestra do professor Attico Chassot e novas conversas entre colegas e professores acontecerem.

A solicitação de produzir um texto em gênero diferente do primeiro e daquele lido está imbuída na crença de que, ao possibilitar aos educandos tal produção, estaria-se colocando-os em situações de comunicação mais próximas das reais possíveis, que podem ser mais significativas e proporcionar o domínio das tarefas necessárias a tal atividade. Sob esse prisma, espera-se o afloramento de capacidades que logrem ultrapassar o gênero escrito, isto é, a capacidade de transferir características textuais e habilidades à produção de outros gêneros, sejam mais próximos ou distantes em termos das características textuais.

A análise dos dados considerou aspectos estruturais e composicionais (ou a infraestrutura geral) dos textos escritos pelos licenciandos, sobretudo itens como extensão, formato da produção e a tipologia textual. Nessa, também foram levados em consideração os aspectos que influenciaram a produção, empregando-se a perspectiva crítica freiriana, em especial a relação leitura de mundo/da palavra e a curiosidade epistemológica, além dos apontamentos de Koch e Elias (2010) no que diz respeito à estruturação da leitura e da escrita. A análise ainda focou os aspectos do conteúdo dos textos produzidos, ou seja, quais sentidos, a partir da leitura, foram explicitados por meio da escrita. A discussão calcou-se, principalmente, nas proposições de Kleiman (2008) acerca das estratégias de leitura, assim como na perspectiva crítica de leitura de Freire (2008) e Ezequiel Silva (2003, 2009).

\section{RESULTADOS E DISCUSSÃO}

Como mencionado, a produção textual se deu em dois momentos, logo após a leitura do livro e ao fim da atividade. Na primeira situação, 33 licenciandos participaram e foram produzidos 13 textos, sendo 3 poesias, 3 histórias em quadrinhos, 3 cartas e 4 artigos de opinião. Vale o destaque que um mesmo grupo elaborou 2 poesias, uma que retratou o tema mulher e outra que retratou o negro. No segundo momento foram entregues 12 textos, sendo dessa vez 2 poesias, 3 histórias em quadrinhos, 4 cartas e 
3 artigos opinativos. $\mathrm{Na}$ segunda vez, um total de 30 licenciandos participou da produção.

De um modo geral, o artigo de opinião foi relatado como o gênero com o qual tinham menos contato. Assim, os educandos responsáveis pela produção desse gênero relataram ter lido em jornais e revistas muitos textos dessa natureza. No caso da poesia, apesar do contato desde os tempos escolares, os educandos relataram que esse gênero também foi bastante buscado, procurando-se maior proximidade antes de escreverem o deles. Segundo Freire (2008, p. 30),

Um exercício crítico sempre exigido pela leitura e necessariamente pela escrita é o de como nos darmos facilmente à passagem da experiência sensorial que caracteriza a cotidianidade à generalização que se opera na linguagem escolar e desta ao concreto tangível. Uma das formas de realizarmos esse exercício consiste na prática a que me venho referindo pela "leitura da leitura anterior do mundo" $[\ldots]$

Ao buscarem a leitura dos gêneros textuais em que tinham de produzir, os educandos estão efetuando a leitura da leitura anterior de mundo. Perseguem a compreensão de um objeto que está no domínio da cotidianidade e que devem generalizar em sua escrita. Isto é, eles visam escrever um texto com características similares, como forma de balizar a produção. A partir da experiência sensorial de buscarem textos no cotidiano, conseguiram generalizar as características textuais na concretude da escrita, em um exercício no qual a aproximação ao objeto vai se tornando mais metódica e mais rigorosa. A busca por essa leitura se torna curiosa, epistemologicamente, no sentido freiriano do termo, "[...] como inquietação indagadora, como inclinação ao desvelamento de algo [...] como procura de esclarecimento, como sinal de atenção que sugere alerta." (FREIRE, 2006, p. 32). Não é apenas um trabalho de leitura, também é prático, uma vez que proporciona a apropriação de um novo gênero por meio da produção textual, o que parece ser mais produtivo comparado a explanações teóricas do que seja um ou outro gênero. O conhecimento desses gêneros é o que propiciará aos sujeitos, quando forem chamados a se comunicar, escolherem um ou outro para uma determinada situação.

Em termos de características textuais, não houve diferenças significativas entre os primeiros textos produzidos e aqueles redigidos ao 
fim da pesquisa. Todos os textos apresentaram-se estruturalmente em um formato padrão. Em outras palavras, os textos se coadunam com um formato aceito socialmente para cada gênero. Isso indica que os educandos foram capazes de incorporar em suas produções as características composicionais que diferenciam os gêneros em pauta.

As cartas, por exemplo, são compostas por: cabeçalho, saudações iniciais, desenvolvimento do tema, saudações finais, autores, data e local. Esses são denominados contextualizadores, sendo imprescindíveis ao gênero epistolar e outros símiles, como bilhetes e telegramas (KOCH; ELIAS, 2010). A única variação é a presença de data e local no início da carta, o que também é comum. Aquele que escreve pode adaptar o modelo do gênero ao seu próprio estilo. Os destinatários foram diversos (professora da disciplina, amigos, o autor da obra, familiares). A extensão sempre variou de uma página a uma página e meia, escritas à mão ou digitadas. Nas cartas prevaleceram as sequências narrativas, expositivas e descritivas. Em alguns poucos casos verificou-se também sequências injuntivas, predominando a escrita em linguagem ativa, na primeira pessoa do singular ou do plural.

Em alguns enunciados presentes nas cartas foi constatada a ausência de sinais de pontuação, como no início da carta apresentada no Quadro 1. Essa é uma das marcas da oralidade na escrita, sendo comum em textos escritos por quem está se adequando a essa produção $(\mathrm{KOCH}$; ELIAS, 2010), o que revela, portanto, algumas das dificuldades de parcela dos educandos.

Os artigos de opinião, por sua vez, encerram uma tipologia predominantemente expositiva e argumentativa, aparecendo trechos descritivos. Em geral foram digitados (apenas um foi escrito à mão) e tiveram extensão média de uma página. Usualmente foram escritos em linguagem passiva, na terceira pessoa e, em algumas situações, em primeira pessoa do plural. No Quadro 2 é apresentado um trecho de um dos artigos de opinião produzidos, com destaque para os tipos textuais identificados.

No caso das histórias em quadrinhos, todas apresentaram diálogos entre personagens (dialogal), predominando o discurso direto, típico desse gênero (Figura 1). Também são perceptíveis trechos narrativos nos quais os personagens são os narradores de fatos históricos e histórias. Outra característica peculiar é concernente às personagens das histórias, que variam desde aquelas criadas (inventadas) especificamente para a atividade a 


\section{Quadro 1}

Trecho de uma das cartas escritas pelos educandos com destaque para a presença de variados tipos textuais.

\begin{tabular}{|c|c|}
\hline $\begin{array}{l}\text { Espero que você esteja bem e com muita vontade de voltar } \\
\text { para o curso e não perder as oportunidades de se encher dos } \\
\text { conhecimentos e informações que essa universidade nos } \\
\text { proporciona como foi a palestra A ciência é masculina que tive o } \\
\text { prazer de assistir, ministrada pelo professor Chassot. }\end{array}$ & $\begin{array}{l}\text { Narrativa } \\
\text { Apresenta um evento/ } \\
\text { situação }\end{array}$ \\
\hline $\begin{array}{l}\text { Sabemos que a educação e a cultura são forças transformadoras } \\
\text { da sociedade e do mundo, e que a constituição é um direito de } \\
\text { todos, mas hoje em dia não é o que vemos. }\end{array}$ & $\begin{array}{l}\text { Argumentativa } \\
\text { Introdutora de opinião }\end{array}$ \\
\hline $\begin{array}{l}\text { Diante deste fato é que o cientista escreveu seu livro A ciência } \\
\text { é masculina, É sim senhora. Pode-se perceber que para justificar } \\
\text { tal afirmação ele buscou analisar nossas raízes gregas, judaicas } \\
\text { e cristã, além de explicações históricas e biológicas. Na leitura } \\
\text { do livro observa-se que o preconceito contra a mulher não só na } \\
\text { ciência mas na maioria das produções humanas ainda é grande } \\
\text { e vem de muito longe. Uma enorme diferença é em relação ao } \\
\text { premio nobel, que desde sua criação apenas } 12 \text { mulheres foram } \\
\text { contempladas nas áreas de física, química e medicina. }\end{array}$ & $\begin{array}{l}\text { Expositiva } \\
\text { Síntese de representações } \\
\text { conceituais }\end{array}$ \\
\hline $\begin{array}{l}\text { Dessa forma, as políticas públicas têm que ser renovadas e dar } \\
\text { maior ênfase à mulher na ciência (...). }\end{array}$ & $\begin{array}{l}\text { Injuntiva } \\
\text { Prescrição de aç̃̃es }\end{array}$ \\
\hline
\end{tabular}

personagens adaptadas de outros contextos (meninas superpoderosas) e até aos próprios educandos. $\mathrm{Na}$ criação das histórias, os estudantes empregaram basicamente desenhos à mão livre e programas de computação.

Um aspecto em comum depreendido da análise desses três primeiros gêneros é o fato de todas as cartas, os artigos de opinião e praticamente todas as histórias em quadrinhos (com exceção de uma) serem iniciados com a descrição do contexto da produção (leitura de um livro que retrata as diferenças quantitativas entre homens e mulheres laureados com o prêmio Nobel). Esse é um dos aspectos diferenciadores desses gêneros em relação à poesia, em que a inclusão do contexto de produção é menos viável e se dá de maneira mais implícita devido à extensão do texto.

A inserção desse contexto decorre de uma característica importante da escrita, que é sua perspectiva dialógica entre autor e leitor. Para Koch e 
Elias (2010), quando o autor pensa no leitor, ele recorre a diversas estratégias linguísticas, textuais, cognitivas e interacionais, tal qual o contexto, vendo e revendo o percurso de sua produção. Logo, está se tornando consciente das relações sociais de comunicação. Ao fazer esse exercício de pensar em seu interlocutor, o autor está transformando o processo de escrita em um processo controlado, portanto metacognitivo.

No caso das poesias, todas foram construídas em versos e estrofes. A extensão não variou muito, de 20 a 30 versos. Em algumas foi observada a presença de rimas, mas essa não foi uma característica constante em todas.

Algumas delas não apresentaram títulos. As poesias também foram marcadas pela criatividade, típica da linguagem artística, além de comparações,

\section{Quadro 2}

Trecho de artigo de opinião produzido na atividade.

Desde 1901 o prêmio Nobel é distribuído em várias áreas entre elas as de diplomacia ou paz, literatura, química, fisiologia ou medicina e física. Na área de ciências temos 529 ganhadores entre eles 13 mulheres, e em física, 3 em química e 8 em medicina ou fisiologia - apenas 3 não dividiram trabalho com homens, $2 \mathrm{em}$ química e 1 em medicina. Entre todos nenhum negro.

Observa-se que a discriminação com a mulher dificultou que esta recebesse prêmios nobeis. Como principais motivos para esse acontecimento, Chassot, procura provar que a contribuição dessas três raízes - a grega, a judaica e a cristã, construíram uma sociedade machista na qual a ciência não é uma exceção. Onde as mulheres eram e ainda são em alguns países atualmente submissas ao home, ela foi considerada a desgraça de alguns fatos como comer a fruta do mal (Eva) e na mitologia grega (Pandora).

A religião e a ciência andam sempre juntas, uma criando e a outra contestando, ocupando dessa maneira a cabeça das pessoas. A discriminação das mulheres ocorre em muitos ramos não só da ciência, mas como em outras atividades, como o ingresso na política e universidades, que ocorreram de maneira tardia, devido à proibição de sua entrada. Um dos fatores que também influenciaram para a pequena participação das mulheres na ciência é o fato da maternidade, que acabavam a retirando de seus estudos por um determinado tempo (...), mas essa situação mudou com a descoberta dos métodos contraceptivos.

\section{Descritiva}

Apresentação qualidades, componentes, propriedades etc

\section{Expositiva}

Síntese de representações conceituais

\section{Argumentativa}

Introdutora de opinião 


\section{Figura 1}

História em quadrinhos desenhada à mão com personagens inventados.

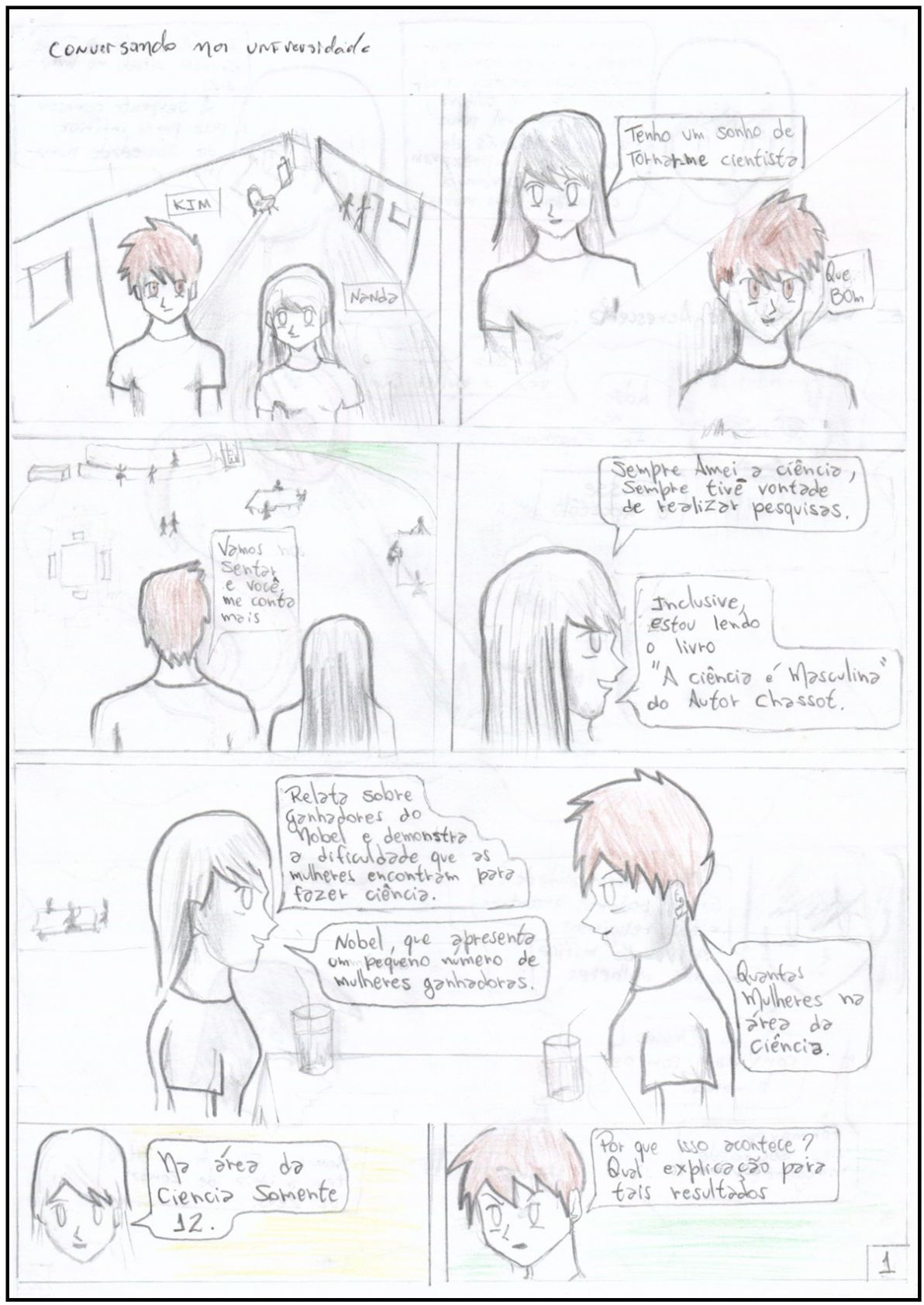


tais quais metáforas e analogias, como evidencia-se na transcrição de duas delas (Quadro 3). Uma característica diferencial dessas poesias em relação às demais é a riqueza de recursos de ordem fonológica, em especial a entonação, o ritmo e a rima. Tais recursos atuam na sensibilização do leitor.

No caso da poesia da esquerda, percebe-se que os autores estabelecem uma série de metáforas para o homem (sol, ying, bem, sorte) e para a mulher (lua, yang, mal, azar) na comparação entre ambos. Também

\section{Quadro 3}

Poesias produzidas com recursos linguísticos e de ordem fonológica.

Homem e Mulher

Sol e Lua

Ying e Yang

Bem e Mal

Sorte e Azar

A mulher a desgraça

0 errado, 0 impróprio

0 homem o provedor

0 protetor 0 comunicador

Prêmio Nobel é apenas homens?

Quase e exclusivo sim

Apenas 12 mulheres em

Mais de 400 homens

Azar ou discriminação

Falta de vontade ou

Falta de oportunidade?

Dedicação aos filhos, marido

E casa ou dedicação a ciência

Buscando novas descobertas e

Novos dilemas?

Este é o problema

Para onde devemos ir?

Que caminhos devemos seguir?

Ou as oportunidades irão surgir

Para isso devemos reagir.

\section{Sem título}

Em palavras de mulher

Colocadas numa rima

Fica claro que a vida

É masculina e feminina

Da a união entre os dois sexos

É que começa toda a vida

Se a ciência é masculina

É porque o homem pensa

E a mulher rumina!

Mas a condição da vida

É a sabedoria feminina!

Porque o pensar ser só do homem

Isso não é uma sina

É mania de tempo antigo

Injusto e machista

Superado há um bom tempo

Pela liberalização feminista!

Mas o premio Nobel

Houve uma superação

Que nos tempos modernos

Não há mais discriminalização

Um negro e doze mulheres

Mudaram a nossa visão! 
é identificado um recurso visual que estabelece um jogo de palavras entre o título e as metáforas utilizadas na primeira estrofe. O título da poesia tem a palavra "homem" do lado esquerdo e a palavra "mulher" do lado direito, estando todas as metáforas relacionadas ao homem, no lado esquerdo, e as relacionadas à mulher, no lado direito. Já na segunda estrofe é possível perceber recursos anafóricos (a mulher a desgraça/o errado o impróprio/O homem o provedor $\mathbf{o}$ protetor $\mathbf{o}$ comunicador) que enfatizam a mensagem do texto e o tornam rico em estilo linguístico e enquanto produção textual. Embora em menor grau, o uso de metáforas também está presente na poesia da direita, até com uma forçosa metáfora que produz rima (ciência masculina - mulher rumina) e certo humor. A presença desses recursos foi típica do gênero poesia e eles funcionaram dando contornos artísticos aos textos.

Pôde-se entrever que as condições de produção textual influenciam essa produção. É difícil afirmar se o uso dos recursos linguísticos e fonológicos foi consciente, mas a memória que os educandos têm desse gênero pode abarcar a presença de tais recursos. O contato, na vida cotidiana, seguramente influencia quando da produção e intelecção de textos.

Para a atividade de escrita, o produtor precisa ativar "modelos" que possui sobre práticas comunicativas configuradas em textos, levando em conta elementos que entram em sua composição (modo de organização), além de aspectos do conteúdo, estilo, função e suporte de veiculação. (KOCH; ELIAS, 2010, p. 43).

Não somente a ativação desses modelos de textos, mas a busca por esses gêneros no momento de produzir o seu parecem ter relação com as características observadas. Como já reportado, sobretudo no caso daqueles que escreveram poesias e artigos de opinião, muitos exemplos foram lidos para consubstanciar a escrita. É pela comparação dos textos com os quais tem contato e pela representação que tem deles na memória que o escritor constrói o seu texto. De certa forma, os gêneros escolhidos estão muito presentes na vida desses estudantes. Entretanto, escrevê-los não é a mesma coisa do que lê-los ou do que ter contatos incipientes. De acordo com Freire (2008, p. 33): "Estudar é desocultar, é ganhar a compreensão mais exata do objeto, é perceber suas relações com outros objetos. Implica que o estudioso, sujeito do estudo, se arrisque, se aventure, sem o que não cria nem recria." 
$\mathrm{Na}$ comparação entre os textos, os educandos conseguiram criar e recriar os seus, o que se mostrou interessante, pois foram capazes de estabelecer relações e principalmente sentidos entre o texto lido e os produzidos. Essa é uma das características primordiais da leitura crítica. Além disso, a atividade proporcionou ações discursivas em situações definidas com o auxílio de uma ferramenta específica, o gênero textual, cujo domínio pelos educandos parece ter sido satisfatório. Para Koch e Elias (2010, p. 61): "Dominar um gênero consistiria no próprio domínio da situação comunicativa, domínio esse que se pode dar por meio do ensino das aptidões exigidas para a produção de um gênero determinado." Pensando na leitura crítica como uma ferramenta indispensável ao exercício consciente da cidadania, cujas situações comunicativas estão em seu cerne, o ensino dos gêneros é uma forma de conceder poder de atuação a educandos e educadores. A partir do momento em que os educandos passam a trabalhar essa produção de maneira intencional, refletindo sobre aquele que irá ler o seu texto e, portanto, regulando o que escreve a partir de leituras e releituras, está exercendo práticas necessárias à inserção crítica no mundo. Dessa forma, conforme defende Silva (2002), a leitura-escrita passa a ser então uma via de acesso à participação na sociedade.

A intertextualidade foi outro aspecto muito marcante. Ficou evidente em todas as produções o apoio às ideias presentes no livro para a construção textual. $\mathrm{O}$ fato de a mulher ser, desde tempos remotos, tratada como inferior ao homem é enfatizado unanimemente nos textos, ainda que não sejam explicitadas as causas dessa "inferioridade" em alguns, exemplos que se apresentam a seguir.

O livro relata sobre o preconceito existente contra as mulheres na sociedade antiga [...] ele nos mostra uma realidade vivida a uns séculos atrás onde a mulher não podia ter a sua liberdade, assim ficando submissa [...] (trecho extraído de uma das cartas).

Na leitura do livro observa-se que o preconceito contra a mulher não só na ciência mas na maioria das produções humanas ainda é grande e vem de muito longe. (trecho extraído de um dos artigos de opinião).

Essa percepção da história permite analisar tais fatos sob uma nova perspectiva, uma interpretação e reescrita do lido, o que vem ao encontro daquilo que está sendo defendido como leitura crítica. Aproveitando as 
próprias falas de Chassot (2009, p. 20, grifo do autor), “[...] nós, educadores e educadoras, temos também o ofício acometido aos historiadores: lembrar o que os outros esqueceram."

Diferentemente de outras pesquisas, as quais relatam que os leitores menos desenvolvidos, ao se posicionarem frente ao texto, geralmente concentram-se em problemas com palavras soltas ou empregam cópias integrais do texto lido (FRANCISCO JUNIOR; GARCIA JÚNIOR, 2010; MATURANO; MAZZITELLI; MACÍAS, 2003; SANTOS; QUEIROZ, 2007), a produção de um outro gênero potencializou o uso de um discurso próprio logo na primeira produção. Isso evidencia um deslocamento do nível de problematização, influenciado, provavelmente pelas condições de leitura. Para ilustrar tal aspecto, são apresentados dois excertos retirados, respectivamente, de um artigo de opinião e de uma carta.

Desde o início dos tempos a sociedade tem um grande histórico de machismo, considerando a mulher como um ser inferior tanto fisicamente como intelectualmente em diversos casos. Os de maior domínio são os religiosos, onde as mulheres são vistas como as responsáveis por todos os males causados aos homens. As mais conhecidas são as história de Pandora e Eva, ambas a primeira mulher a ser criada, aquela sendo criada por Zeus para castigar os humanos liberando todo o mal existente e esta sendo criada por Deus para ser submissa a Adão e o levou a cometer o pecado da desobediência, sendo expulso do paraíso (trecho extraído de um dos artigos de opinião).

Escrevo para lhe informar que dos 529 laureados do prêmio Nobel, apenas 13 são mulheres: $2 \mathrm{em}$ física, $3 \mathrm{em}$ química e $8 \mathrm{em}$ medicina. Sendo que apenas 3 não dividiram o prêmio com homens, 2 em química e 1 em medicina. Este resultado não é por acaso, nossa origem Grega-Judaico-Cristã é baseada em restrições às mulheres em diversas áreas [...] na mitologia grega dizia que foi com a chegada da mulher ao mundo que veio a perda da felicidade plena dos homens. Outro fato marcante na tradição judaica [...] incorporada pela cultura cristã, que diz que a mulher é produzida do homem e criada a partir de uma costela. Sendo estes textos interpretados de forma machista foi utilizado para discriminar as mulheres deixando-as reclusas ao lar (trecho extraído de uma das cartas).

Nos dois casos nota-se a tentativa de buscar nas raízes históricas a explicação de fenômenos sociais (a discriminação da mulher) ainda vigentes. Não obstante todos se calcarem em uma mesma hipótese base, que possivelmente foi influenciada pela questão de pré-leitura e pela estrutura 
dedutiva do livro, as formas com que as explicações são colocadas diferem entre si, além de não serem cópias literais.

Pode-se inferir, portanto, que a produção de um texto em gênero diferente catalisa uma importante característica da leitura crítica, a produção de um texto próprio do leitor (SILVA, 2002, 2003, 2009) a partir da recriação, da reinvenção do texto original que é a materialização do(s) sentido(s) a partir dele construído(s).

Leitura sem compreensão e sem recriação de significado é pseudoleitura, é um empreendimento meramente ôntico. [...]. Enquanto um projeto de busca de significados, a leitura deve ser geradora de novas experiências para o indivíduo [...] o ato de ler sempre pressupõe um enriquecimento do leitor através do desvelamento de novas possibilidades de existência. (SILVA, 2002, p. 96).

Vivenciar novas situações, experimentar novos caminhos, elucubrar novas possibilidades que permitam materializar o pensamento em escrita contribuem para outras possibilidades do estar no mundo. Escrever um texto estrutural e linguisticamente diferente daquilo a que se está acostumado pode contribuir nessa jornada. A maioria dos participantes nunca havia produzido poesias, histórias em quadrinhos ou artigos de opinião antes. Mesmo as cartas nunca haviam sido escritas com tal finalidade. $O$ fato de terem de escrever exige a regulação do processo de leitura.

A pergunta inicial (a qual deviam responder com o texto escrito) estabelece foco e objetivos para a leitura, propiciando maior controle da atividade e melhor compreensão textual, conforme já assinalado por Kleiman (2001). Com a criação e recriação, torna-se possível contingenciar o caráter reprodutor que acomete a leitura escolar há tempos e diminui o seu caráter crítico. Indubitavelmente, a leitura, a experiência, a história de vida, o fato de ter sido uma produção em grupo encerraram papel primordial e podem ter contribuído. Ainda assim, como o papel do educando não é reproduzir, a criação ganha maior conotação na configuração de novos gêneros. Logo, a escrita auxilia na transformação da leitura em atividade de metacognição.

A poesia apresentada no Quadro 4, por exemplo, retrata de forma bastante sintética os principais sentidos percebidos, sendo construída com um recurso linguístico de certa forma complexo, a inversão de sentido ou ironia. A mensagem que os autores desejam transmitir está implícita no texto, na realidade, ela é inversa ao que está explícito, provocando uma quebra em relação ao que é esperado e ao propósito do texto. 


\section{Quadro 4}

Poesia que retrata sinteticamente os sentidos mais explicitados na produção textual.

\section{Subjugadas}

Na mitologia, religião ou tradição

Ela é humilhada, submissa, castigada, pela

Serpente foi enganada e ao mundo trouxe a desgraça

Como punição aos que o fogo do Olimpo ganharam

A mulher por Zeus foi dada,

Ela é inferior, ela é amaldiçoada,

Nas chamas da fogueira foram as bruxas

exterminadas

Eu sou o sol, tu és a lua, sou superior,

Veja meu brilho, sinta meu calor,

Ajoelha-te perante a mim.

Sua luz à noite é

Apenas meu reflexo.

Os afazeres de casa te esperam

Faça da cozinha o teu laboratório [...]

A ciência não é tua, não te pertences,

Não podes se igualar ao homem, não

Terá capacidade para superá-lo, não

Poderás competir com ele, apenas sirva-0.

Infeliz de Adão que foi persuadido por Eva

Ela era tão venenosa quanto aquela cobra

Perderam o paraíso por sua culpa,

Mas apesar de tudo isso meu Deus,

Meu Deus masculino, Ihe agradeço por não

Ter nascido mulher.

Os autores brincam e problematizam com o fato de a figura de Deus ser predominantemente masculina (Jeová, Jesus, Alá), independente da cultura. Também empregam o tom irônico, como no trecho "Mas apesar de tudo isso meu Deus/Meu Deus masculino, lhe agradeço por não/Ter nascido mulher". 
O texto poético é condensado e pode implicar em muitas significações para quem lê e/ou escreve. Por sua natureza condensada, carreia muitas informações em pouco espaço, o que faz com que elas nem sempre sejam percebidas no primeiro momento. No caso das poesias produzidas, a linguagem poética está cheia de argumentos, muitas vezes pouco evidentes, haja vista que o contexto, essencial à interpretação, não é explicitado como ocorre com os outros gêneros. Alguém que lesse a poesia sem saber a que ela se refere poderá achar a mesma machista, pois apenas o cotexto (aquilo que aparece nas linhas) é insuficiente para que o leitor depreenda um sentido coerente com a intenção discursiva.

A compreensão só é possível se autor e leitor compartilharem de um mesmo conjunto de conhecimentos, denominado contexto sociocognitivo (KOCH, ELIAS, 2010), e quem realiza a atividade escrita terá mais sucesso se estiver consciente da relevância desse aspecto. Ao terem em mente que a poesia era destinada àqueles que conheciam o tema, os educandos parecem intencionalmente fazer uso da mensagem implícita, desvelando um processo interativo consciente. Pode-se perceber o seu contexto de produção, por exemplo, no uso de exemplos retirados da obra lida (mitologia, religião, preocupação com afazeres domésticos).

Ao mesmo tempo, dado que a obra lida retratava enfaticamente a questão das mulheres e não dos negros, muitos educandos talvez não tenham ficado à vontade para discorrer acerca desse tema (também presente na pergunta de problematização inicial). Assim, se alicerçaram no objeto de leitura para compor o texto escrito. As condições históricas às quais os educandos estão submetidos possivelmente não abriram espaço para reflexões em torno do racismo. A retomada pelo autor, em diversos momentos, da tese central da obra, empregando para isso repetições, intercalações e destaques, também pode ter feito com que os educandos se detivessem a esse aspecto em maior grau.

Há estudos que evidenciam o papel dos destaques e repetições na compreensão textual do leitor. Mayer, Dyck e Cook (1984), por exemplo, reportam um estudo que envolveu a leitura de uma passagem de um texto científico que também continha uma relação de causa e efeito. Os resultados mostram que a inclusão de definições de termos chave do texto e a sinalização de relações importantes entre os conceitos são formas de auxiliar os leitores a selecionarem pontos centrais do texto e estabelecerem 
as relações chave, organizando a conexão entre elas. Os autores até propõem essa estratégia como forma de realçar passagens importantes dentro do texto, no intuito de auxiliar os leitores. Nesses termos, as características textuais influenciam. O texto de Chassot apresenta uma relação de causa e efeito de forma dedutiva. Ou seja, é apresentada uma situação (predominância de homens no prêmio Nobel), estabelecendo-se relações gerais (o tratamento da mulher historicamente, sobretudo nas culturas cristã, judaico e grega) que são aplicadas a casos particulares (a primeira mulher a se tornar professora de um curso de engenharia, entre outros). Pandiella, Torné e Macías (2004), utilizando textos sobre o tema pressão extraídos de livros didáticos, concluem que uma estrutura textual dessa natureza (dedutiva) contribui mais efetivamente para as conexões que o leitor estabelece em relações entre causa e efeito.

Ainda assim, para os poucos estudantes que se debruçaram sobre a análise do fato de nenhum negro ter sido laureado com o prêmio Nobel na área das ciências naturais (Figura 2), os argumentos aparecerem balizados por uma questão histórico-social, em concordância com alguns trabalhos acerca do tema (FRANCISCO JUNIOR, 2008). Isso demonstrou uma reflexão para além das linhas do texto, outra característica de criticidade na leitura (SILVA, 2009).

Uma decorrência importante da produção textual em gêneros diferentes daquele lido é a construção de um texto com palavras e características próprias, ainda que apoiado e/ou amalgamado com o que foi lido. A seguir é transcrito trecho de outra poesia que se destaca por reflexões além das linhas.

A Ciência gira em torno do saber Do fazer concreto da experiência compartilhada

E do conhecimento circundante A visão poética cresce da intuição criativa Da experiência humana singular e do conhecimento do poeta

(trecho extraído de uma das poesias).

No trecho transcrito, os autores buscam marcar diferenças entre ciência e poesia. O principal argumento é que a ciência é uma produção racional enquanto a poesia é de caráter emocional, portanto, singular em seu momento de criação. Enquanto cientistas procuram se aproximar da razão, poetas se aproximam da emoção. 
Figura 2

História em quadrinhos que analisa a questão dos negros calcada no aspecto histórico-social.

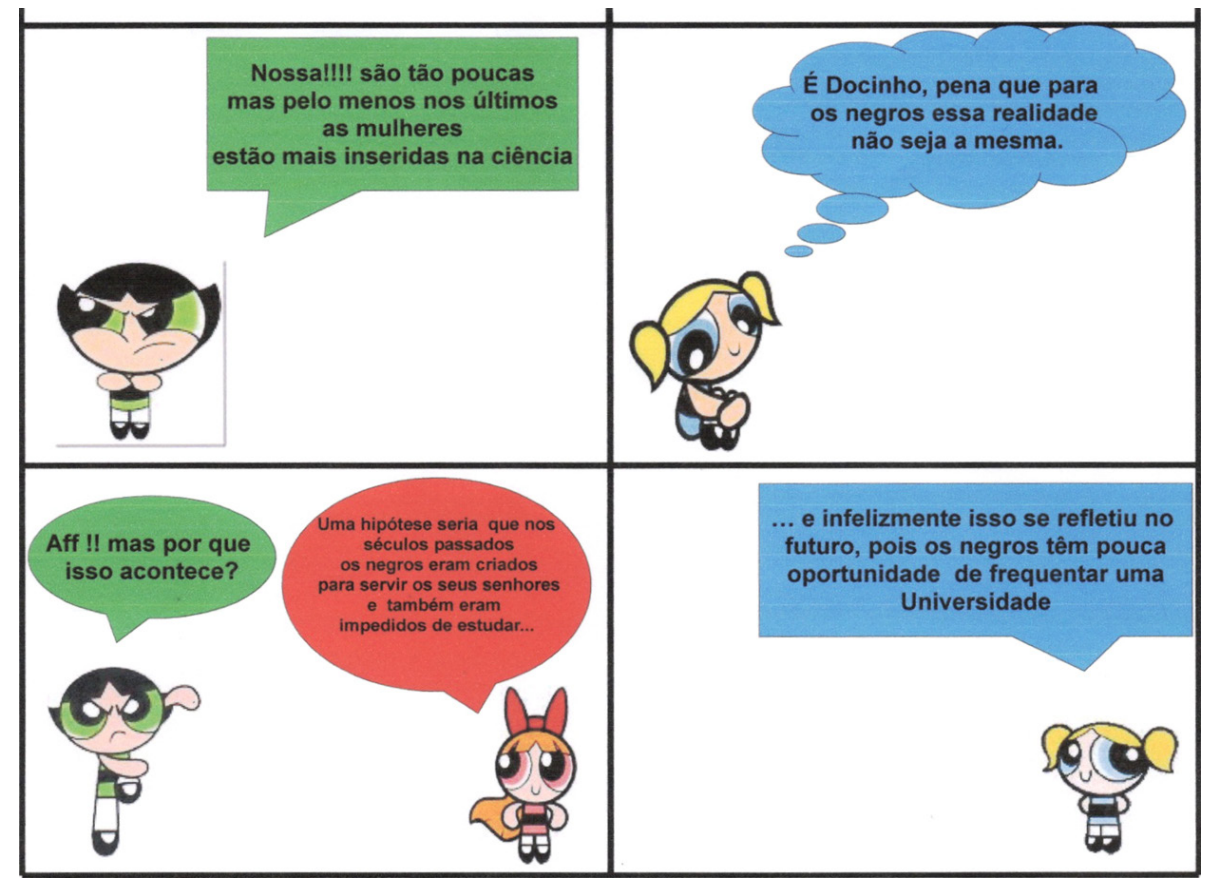

Para além das discordâncias que essa distinção entre ciência e poesia pode causar, a interpretação que parece merecer o destaque aqui é a sensibilidade de seus autores para expressar um sentido próprio, naturalmente idiossincrático e altamente criativo. Isso apenas realça a leitura como uma possibilidade. Para Silva (2002, p. 95): "Ao buscar a intencionalidade, o sujeito abre-se para possibilidades de significação, para as proposições de mundo que os signos do documento evocam ou sugerem." E continua o autor:

Por sua vez, os novos significados apreendidos na experiência do leitor fazem com que este se posicione em relação ao documento lido, o que pode gerar as possibilidades de modificação do texto evidenciado através do documento, ou seja, a incrementação de seus significados. (SILVA, 2002, p. 95).

A produção de textos em vários gêneros na educação em ciências já foi reportada por alguns trabalhos. Utilizando variados gêneros, Souza e 
Almeida (2002) analisaram a presença de conceitos relacionados à fotossíntese em textos produzidos a partir do trecho de uma letra de música. Os textos produzidos apresentaram características literárias, o que diferencia esse tipo de produção textual daquela comumente realizada nas escolas. $\mathrm{O}$ discurso próprio dos estudantes mas muitas vezes associado aos discursos e conhecimentos adquiridos em outros momentos é uma característica importante colocada pelas autoras. O entusiasmo dos estudantes foi um aspecto bastante destacado no trabalho.

Por sua vez, Santos e Queiroz (2007), em pesquisa que envolveu a produção escrita de textos de gênero livre após a leitura de artigos científicos, reportam diferenças na produção de sentidos conforme o gênero. A carta, por exemplo, favoreceu uma perspectiva mais dialógica e trouxe o contexto da produção, isto é, as atividades que a precederam. O discurso poético também esteve presente, na forma de poesia e como paródia de uma canção. Nesses casos, os estudantes imaginam um interlocutor e expressam ideias com sentido. Também em pesquisa que empregou gênero livre para a produção escrita, Resende, Ferreira e Queiroz (2010) encontraram textos literários, textos jornalísticos, textos de informação científica, textos instrucionais, textos epistolares (cartas), textos humorísticos (histórias em quadrinhos) e diários. Os autores enfatizam a qualidade e a criatividade dos textos, refletindo brevemente sobre os benefícios formativos dessa atividade no desenvolvimento de habilidades como criatividade, argumentação e senso crítico.

O que parece ser uma marca comum na produção textual em gêneros é a não repetição por si, isto é, os participantes se assumem na condição de produtores do texto e não compiladores, tornando-se os responsáveis pelo próprio discurso, o que acaba resultando em maior criatividade. Soares e Coutinho (2009), em análise das resenhas produzidas por estudantes após a leitura de fragmentos de artigos de Lamarck, Wallace e Darwin, postulam que, em geral, a construção textual teve em vista outros discursos, sobretudo do autor, mas também o discurso próprio, com o aumento de sequências argumentativas.

\section{À GUISA DE CONCLUSÃO}

A despeito do relato de algumas pesquisas, pouco se sabe acerca de como os estudantes, independente do nível de ensino, produzem textos 
relacionados à ciência em diferentes gêneros, assim como as diferenças que marcam o uso deste ou daquele gênero. De tal maneira, a real contribuição do trabalho com gêneros na prática comunicativa em ciências é uma lacuna. Há escassas informações, também, sobre as dificuldades e a percepção dos estudantes na construção dos textos.

Sobre isso, é possível assinalar que os educandos não estão habituados a trabalhar com diferentes gêneros, especialmente em termos de produção textual, o que demandou busca por material, em alguns casos, e pode explicar a dificuldade encontrada por parte dos estudantes. Vale ressaltar, no entanto, que o trabalho em grupo pode ter minimizado dificuldades individuais, além de ter tornado o texto produzido mais rico, tanto conceitual quanto linguisticamente, apesar de o entusiasmo pela tarefa não ter sido algo tão evidente como em Souza e Almeida (2002).

A escrita de um texto em gênero diferente do lido possibilitou a criação de um texto quase próprio, ainda que em amálgama com o texto lido, evidenciando marcas de intertextualidade. A necessidade de escrever em uma estrutura diferente parece catalisar esse importante aspecto da leitura crítica, a criação e recriação de ideias. Ademais, os sentidos atribuídos à leitura, salvo raras exceções, estão em concordância com a intenção discursiva do autor. Esse aspecto parece decorrer tanto dos objetivos estabelecidos para a leitura quanto da estrutura textual.

Quanto às inferências que podem ser tiradas da estratégia de produção textual em gêneros variados, as poesias e as histórias em quadrinhos possibilitaram maior liberdade de criação, tanto pelo fato de serem também expressões artísticas quanto por serem gêneros cujos modelos são menos fixos em comparação a artigos de opinião e cartas. Tal flexibilidade talvez tenha fomentado maior criatividade aos educandos no momento da exposição de argumentos, opiniões e sentidos produzidos, mas sem que tergiversassem do foco central. Em contraste, nos gêneros carta e artigo de opinião, a diversificação e a alternância dos tipos textuais foram mais frequentes. Cada gênero, pela sua própria natureza, elege as sequências que ocorrerão com maior frequência em sua constituição. De tal maneira, a produção de diferentes gêneros, tanto dos mais quanto dos menos formais, encerra papel preponderante na formação do leitor e, consequentemente, do cidadão crítico. Tendo isso em vista, o ensino da leitura e da produção textual com base em gêneros pode trazer importantes contribuições. 


\section{AGRADECIMENTOS}

À profa. A. C. G. de Oliveira pela abertura na disciplina para que a pesquisa pudesse ser realizada. Aos estudantes participantes, essenciais ao desenvolvimento da pesquisa.

\section{REFERÊNCIAS}

CHASSOT, A. A ciência é masculina? É sim senhora! 4. ed. São Leopoldo: Ed. Unisinos, 2009. $110 \mathrm{p}$.

FRANCISCO JUNIOR, W. E. Educação anti-racista: reflexões e contribuições do ensino de ciências e de alguns pensadores. Ciência \& Educação, Bauru, v. 14, n. 3, p. 397-416, 2008. http://dx.doi.org/10.1590/S1516-73132008000300003

FRANCISCO JUNIOR, W. E; GARCIA JÚNIOR, O. Leitura em sala de aula: um caso envolvendo o funcionamento da ciência. Química Nova na Escola, São Paulo, v. 32, p. 191-199, 2010.

FREIRE, P. Pedagogia da autonomia: saberes necessários à prática educativa. 33. ed. São Paulo: Paz e Terra, 2006. 148 p.

FREIRE, P. Professora sim tia não: cartas a quem ousa ensinar. 19. ed. São Paulo: Olho d'água, 2008. 127 p.

KLEIMAN, A. Leitura: ensino e pesquisa. 2. ed. Campinas: Pontes, 2001. 213 p.

KLEIMAN, A. Texto e leitor: aspectos cognitivos da leitura. 11. ed. Campinas: Pontes, 2008. 82 p. KOCH, I. G. V. Desvendando os segredos do texto. 6. ed. São Paulo: Cortez, 2009. 168 p.

KOCH, I. G. V.; ELIAS, V. M. Ler e escrever: estratégias de produção textual. São Paulo: Contexto, 2010. 224 p.

MATURANO, C.; MAZZITELLI, C.; MACÍAS, A. Los estudiantes verifican la consistencia interna de los textos científicos o retienen la primera información que leen? Investigações em Ensino de Ciências, Porto Alegre, v. 8, n. 1, p. 91-105, 2003.

MAYER, R. E.; DYCK, J. L.; COOK, L. K. Techniques that help readers built mental models from scientific text: definitions pretraining and signaling. Journal of Educational Psychology, Arlington, v. 76, n. 6, p. 1089-1105, 1984. http://dx.doi.org/10.1037/0022-0663.76.6.1089 PANDIELLA, S.; TORNÉ, P. V.; MACÍAS, A. Las caracteristicas de los textos de física e su incidencia em la comprensión. Investigações em Ensino de Ciências, Porto Alegre, v. 9, n. 1, p. 27-35, 2004.

RESENDE, F. S.; FERREIRA. L. N. A.; QUEIROZ, S. L. Concepções a respeito da construção do conhecimento científico: uma análise a partir de textos produzidos por estudantes de um curso superior de química. Revista Electrónica de Enseñanza de las Ciencias, [s.1.], v. 9, n. 3, p. 596-617, 2010.

SANTOS, G. R.; QUEIROZ, S. L. Leitura e interpretação de artigos científicos por alunos de graduação em química. Ciência \& Educação, Bauru, v. 13, n. 2, p. 193-209, 2007. http:// dx.doi.org/10.1590/S1516-73132007000200004 
SILVA, E. T. $O$ ato de ler: fundamentos psicológicos para uma nova pedagogia da leitura. 9. ed. São Paulo: Cortez, 2002. 104 p.

SILVA, E. T. Unidades de leitura. Campinas: Autores Associados, 2003. 117 p.

SILVA, E. T. Criticidade e leitura: ensaios. 2. ed. São Paulo: Global, 2009. 105 p.

SOARES, A. D.; COUTINHO, F. A. Leitura, discussão e produção de textos como recurso didático para o ensino de biologia. Revista Brasileira de Pesquisa em Educação em Ciências, São Paulo, v. 9, n. 2, 2009. Disponível em: <http://www.fae.ufmg.br/abrapec/revistas/V9N2/ v9n2a5.pdf $>$. Acesso em 22 jan. 2011.

SOUZA, S. C.; ALMEIDA, M. J. P. M. A fotossíntese no ensino fundamental: compreendendo as interpretações dos alunos. Ciência \& Educação, Bauru, v. 8, n. 1, p. 97-111, 2002. http:// dx.doi.org/10.1590/S1516-73132002000100008

\section{NOTAS}

${ }^{1}$ A obra em questão discute o machismo incutido em diversos setores da sociedade, perfazendo uma análise histórica de como as mulheres foram consideradas inferiores aos homens a partir das raízes judaica, cristã e grega, ao mesmo tempo em que alude a mulheres que se destacaram em meio ao universo masculino no campo das ciências.

Recebido: 02/08/2012

Aprovado: 23/05/2013

Contato:

Universidade Federal de Alagoas Av. Manoel Severino Barbosa, s/n, Bom Sucesso CEP 57309-005 Arapiraca, AL Brasil 